Ilżbieta Szulc-Rojan

\title{
CONTEMPORARY GLACIATION OF THE PAMIRS
}

\author{
GENERAL CHARACTERIZATION OF THE RANGE
}

The Pamirs are located in Central Asia, their greater part lying within the soundaries of the Commonwealth of Independent States, with the remaining sarts belonging to China and Afghanistan. The mountains take almost half of he surface of Tajikistan, i.e. some $70,000 \mathrm{sq} . \mathrm{km}(425 \mathrm{~km}$ of length and $280 \mathrm{~km}$ if width). The range is composed of a system of ridges, primarily of latitudinal rrientation, separated by deep valleys and dales (see Fig. 1).

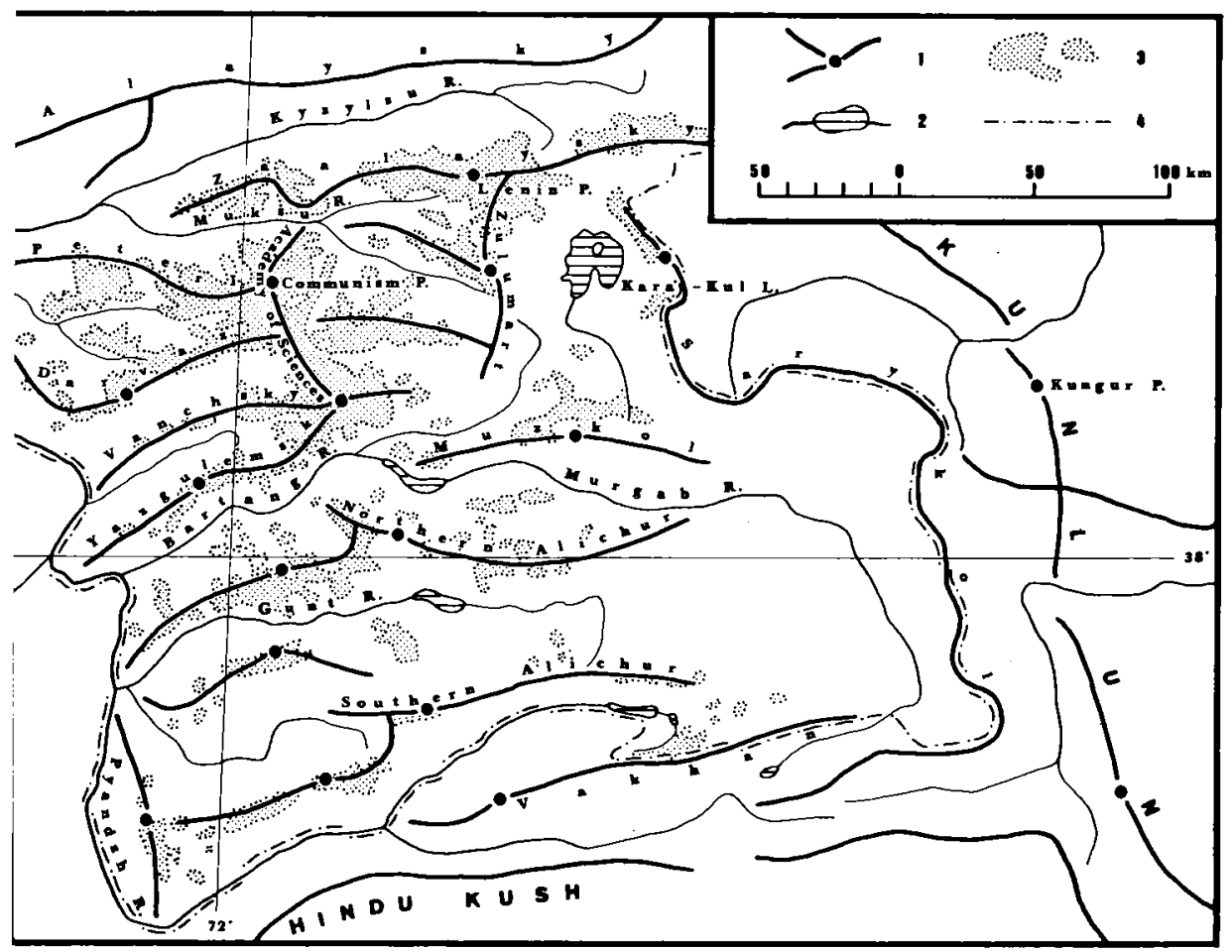

?ig. 1. Orographic sketch of Pamir Mts. showing contemporary glaciation (after Bol'shaya..., 1975)

1 - mountain ridges and peaks, 2 - rivers and lakes, 3 - glaciers, 4 - boundary of Tajikistan 
Owing to the differentiation of landscape the Pamirs are divided into the eastern and western parts. In the Eastern Pamirs the bottoms of valleys and dales are located at the altitude of 3,500 to 4,500 meters a.s.l. Many of them are covered with moraine sediments. They are dominated by ridges of gentle shapes whose relative altitudes reach $1,200-1,800$ meters. The Western Pamirs are strongly cut through by the narrow and deep valleys of rivers flowing westwards. Their bottoms are covered by the fluvioglacial and fluvial sediments. Slopes are partly covered with rock waste. Altitude differences between the valley bottoms and the peaks reach 5,000 meters.

\section{DIMENSION AND EXPOSITION OF GLACIERS}

Glaciers occupy $7493 \mathrm{sq} \cdot \mathrm{km}$ in the Pamirs (Dol'gushin, Osipova, 1989), Fig. 1. The area of an average glacier only slightly exceeds $1 \mathrm{sq} \cdot \mathrm{km}$. Glaciers of less than $1 \mathrm{sq} \cdot \mathrm{km}$ of surface constitute $80 \%$ of all the glaciers and take $15 \%$ of the glacial area. Thus, glaciers of more than $1 \mathrm{sq}$. $\mathrm{km}$ of surface constitute only $20 \%$ of their total number, but account for $85 \%$ of the area presently under glaciation in the Pamirs.

Appearance of glaciers depends upon many factors, including orientation of the slope. Northern slopes, which obtain less solar radiation, have more advantageous conditions for appearance of glaciers. The northern slope glaciers constitute $65-70 \%$ of the total number of glaciers in the Pamirs, with the southern slope glaciers accounting for only $15-20 \%$.

The greatest glaciers of the Pamirs and simultaneously of the Commonwealth of Independent States, are linked with the highest ranges, namely those of Academy of Sciences, Peter I, Yazgulemsk Vanchsky and Zaalaysky (Table 1).

The greatest glaciers of the Pamirs (after Kvachev, 1982)

\begin{tabular}{|l|l|c|}
\hline \multicolumn{1}{|c|}{ Glacier's name } & \multicolumn{1}{|c|}{ River basin } & Surface in sq.km \\
\hline \multicolumn{1}{|c|}{1} & \multicolumn{1}{|c|}{2} & 3 \\
\hline Fedchenko & Muksu & 651.7 \\
Grumm-Grzhemaylo & Bartang & 142.9 \\
Garmo & Obichingou & 114.6 \\
Okt'yabrskiy & Koksay & 88.2 \\
RGO & Wanch & 64.4 \\
Northern Tanymas & Bartang & 55.0 \\
Great Sauk-Dara & Muksu & 53.0 \\
Vitkovsky & Muksu & 50.2 \\
Uysu & Markansu & 49.9 \\
Academy of Sciences & Muksu & 48.4 \\
\hline
\end{tabular}




\begin{tabular}{|l|l|c|}
\hline \multicolumn{1}{|c|}{1} & \multicolumn{1}{|c|}{2} & 3 \\
\hline Rakzou & Yazgulem & 47.2 \\
Sugran & Muksu & 47.1 \\
Nalivkin & Muksu & 45.2 \\
Gando & Obichingou & 44.6 \\
Bivachnyi & Muksu & 37.1 \\
Fortambek & Muksu & 36.4 \\
Vavilov & Obichingou & 34.0 \\
Yazgulemdara & Bartang & 33.8 \\
\hline
\end{tabular}

The largest mountain glacier of the world, Fedchenko, originates from the slopes of Revolution Peak. Its total surface, including some 50 tributaries, amounts to $651.7 \mathrm{sq} \cdot \mathrm{km}$. It flows from 6300 meters of altitude down to 291 meters a.s.l., attaining $77 \mathrm{~km}$ of length. Ice thickness exceeds in some places $800 \mathrm{~m}$, and the volume oscillates around $130 \mathrm{cu} . \mathrm{km}$ (Kvachev, 1982).

\section{CONDITIONS OF APPEREARANCE OF SNOW COVER ON GLACIERS}

The main sources of supply for glaciers are constituted by atmospheric precipitation reaching directly the surface of glaciers and the snow transported by the wind from the surrounding slopes. In some areas of the Pamirs an important role is also played by avalanches.

Precipitation is highly differentiated over the area of the Pamirs. The highest precipitation occurs in its western and north-western parts (1,000-1,500 mm per year on the average), especially on: Peter I, Darvazi and Academy of Sciences ranges. The Peter I Range is also the area of the most frequent and the greatest avalanches and snow storms. The Western Pamirs are characterized by the winter-and-spring maximum of precipitation, while the Eastern Pamirs - by the maximum occurring in summer. The air masses coming from the north-west contain already low quantities of water vapour when they reach the Eastern Pamirs and the southern part of the Western Pamirs, and so precipitation is here much lower than in the NW part of the Pamirs (in the southern part of the Western Pamirs - up to $300 \mathrm{~mm} /$ year, in the Eastern Pamirs - 50-160 mm/year).

Along with the altitude a.s.l. the share of solid precipitation in the total sum increases. The Fedchenko Glacier in the Western Pamirs gets this kind of precipitation during the whole year. Of this precipitation $70 \%$ occurs during cooler months of the year (October-April) and 30\% - during warmer months (May-September). The maximum thickness of the snow cover on the glacier ice tongue occurs in April and reaches $120 \mathrm{~cm}$. In the supplying part the thickness of snow cover reaches $330-450 \mathrm{~cm}$ and is observed at the end of May. The annual average of precipitation on the Fedchenko Glacier at the altitude of $4200 \mathrm{~m}$ a.s.l. is $2240 \mathrm{~mm}$. 
THE BOUNDARIES OF PERMANENT SNOW AND GLACIERS

The altitudes of appearance of the upper and lower boundaries of glaciers and permanent snow (the snow line) depend upon various climatic, orographic and supply factors. In the Western Pamirs the lowest altitude of permanent snow was determined to be 3,600 meters a.s.l., while in the Eastern Pamirs - 5,250 meters (Sannikov, 1982). The difference of this altitude between the extremes of the range reaches therefore 1,650 meters. The limit altitude of appearance of the permanent snow varies often even within the same ridge, and so on the southern slopes of the western part of the Zaalaysky Range this altitude is 4,470 meters a.s.l. and it goes up to 5,260 meters on the southern slopes of its eastern part.

The course of the boundary of permanent snow depends also upon the slope orientation. Thus, it is lower by $300 \mathrm{~m}$ on the northern slopes than on the southern ones.

The lower boundaries of glaciers of the Pamirs, similarly as the snow line, display the tendency to go up from the West eastwards (on the average from 3,650 to 4,860 meters a.s.l.). On the northern slopes the glaciers go dowi by 200-300 lower than on the southern slopes. The glaciers of the Pamirs reach the highest altitude (the upper limit of glaciers) on the slopes of Communism Peak ( 7,200 meters a.s.l.).

\section{MORPHOLOGICAL TYPES OF GLACIERS}

Observations indicate that the Pamirs host all the types of glaciers known from geographical literature, namely: valley, kar, hanging and slope glaciers (Fig. 2).

Valley glaciers originate from kars or dales and flow down to the valleys. Their magnitudes vary considerably - from just a fraction to hundreds of square kilometers. They constitute $1 / 3$ of the number of all the Pamirs glaciers and $2 / 3$ of the total surface of glaciers. Their tongues reach quite low - down to 2,300-3,000 meters a.s.l. Some of them are covered over a large part of surface with the moraine debris (like on the Fedchenko, Garmo, Academy of Sciences, Fortambek and Valter glaciers). In the northern part of the Pamirs the valley glaciers constitute $40-60 \%$ of their total number. This type is especially frequent in the basins of such rivers as Muksu, Vanch and Markansu.

The cirque glaciers fill entirely the kars or flow just slightly beyond the threshold. They constitute only $10 \%$ of the total surface of glaciers in the Pamirs, though in terms of numbers they compete with the valley glaciers. Their fronts reach the elevation of 3,500-4,000 meters a.s.l. The glaciers of this type are under snow during an important part of the year, and even sometimes during the whole year, but their extremes happen to be covered 


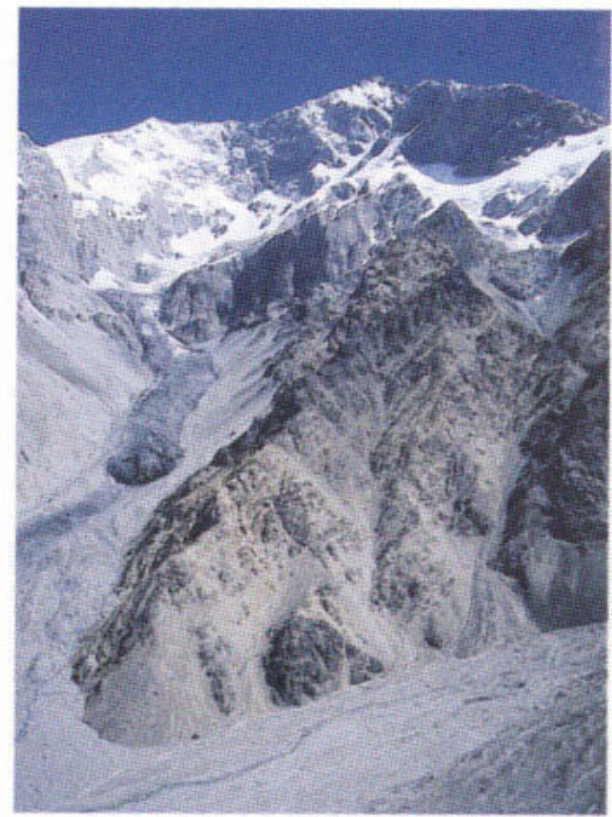

ig. 2. Various types of glaciers (valley, slope nd hanging) on the south-western slope of orzhenevskoy Peak (7105 m a.s.1.) with rock debris. These glaciers are characteristic for the river basins of Surkhob and Kafirnigan, where they account for $40-50 \%$ of all the glaciers.

The slope glaciers (Fig. 3 ) cover the weakly or moderately inclined fragments of mountain slopes, forming extensive patches, frequently from the

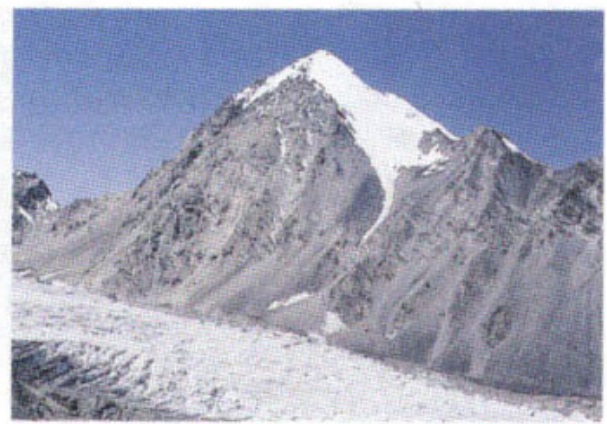

Fig. 3. The slope glacier covering a part of NKVD Peak and the valley glacier Traube (area of Communism Peak)

idge down to the mountain foot. The magnitude of the average glaciers of his type is approximately $0.4-0.6 \mathrm{sq}$. $\mathrm{km}$, sometimes reaching $3-4 \mathrm{sq} . \mathrm{km}$. the slope glaciers are characteristic for the drainage basins of Markansu ind Surkhob rivers and for the region of Kara-Kul Lake.

The hanging glaciers (Fig. 4) are situated on the steep slopes of the nountains. They do not have well developed firn fields. One encounters hem on significant altitudes. They constitute approximately $30 \%$ of the otal number of glaciers in the highest areas of the Pamirs and are most freuently observed in the river basins of Muksu, Murgab and Bartange.

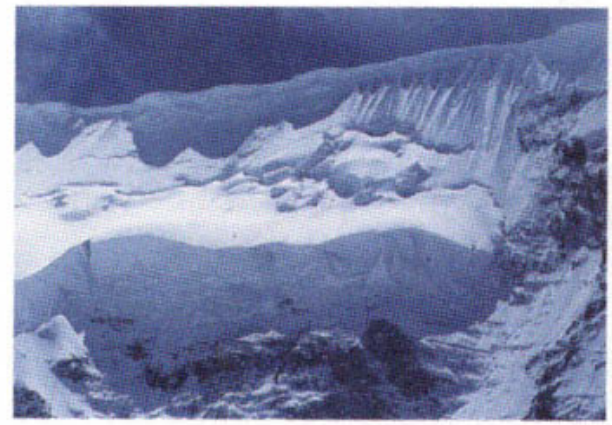

ig. 4. The Academy of Sciences Range with anging glaciers, where intensive mechanial ablation takes place

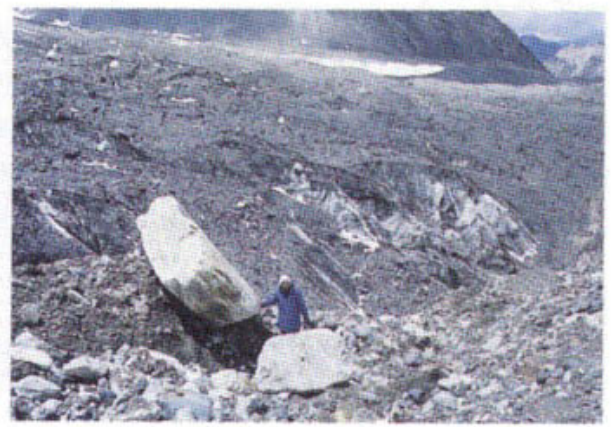

Fig. 5. Moraine cover on Valter glacier, influencing the rate of ablation 
ABLATION

The most important source of heat for the Pamirs glaciers is of course constituted by solar radiation. Radiation of intensity of $697.8 \mathrm{~W} / \mathrm{sq} . \mathrm{m}$, given the albedo of the glacier's surface of $50 \%$, causes during 1 hour melting of a layer of $3.8 \mathrm{~mm}$ of thickness, i.e. 3,800 cu.m of water from $1 \mathrm{sq} . \mathrm{km}$ (Kuznetsov, 1982).

In determining the magnitude of surface ablation with consideration of the heat balance one often refers to simple relations, based upon the linkage between melting and air temperature. During the ablation season the layer of 500-600 cm of thickness melts away on Skogach glacier at the altitude of $3,000 \mathrm{~m}$ a.s.l., while at the altitude of $4,000 \mathrm{~m}$ a.s.l. $-150-350 \mathrm{~cm}$, and at the altitude of $4,500 \mathrm{~m}$ a.s.l. - only $20-160 \mathrm{~cm}$ (Kuznetsov, 1982).

Ablation of glaciers of the Eastern Pamirs is only slight. Observation of the firn part of the Krasnoslabodtsev glacier (southern slope of Zaalaysky Range) indicates that the maximum value of this ablation is $55 \mathrm{~cm}$ during a season (Kuznetsov, 1982). Seasonal melting of the glaciers of Tajikistan starts in the middle of May when the average daily air temperature exceeds $0^{\circ}$ and becomes positive.

The seasonal snow cover on the glacial tongues usually melts away in July and in the beginning of August, after which melting of ice follows. The intensity of this process changes from 6 to $8 \mathrm{~mm}$ per $1^{\circ}$ of temperature increase during the ablation season (Kuznetsov, 1982).

Due to existence of moraine covers on glaciers' surfaces melting occurs with varying speed, even within one glacier (Fig. 5). In the years 1961-1962 the melting of the Medvezyi glacier under the moraine cover of up to $2 \mathrm{~cm}$ of thickness was equivalent to $120 \%$ of melting of pure ice, under the cover of $5 \mathrm{~cm}$ of thickness $-51 \%, 10 \mathrm{~cm}-21 \%$. Similar study was carried out on the Skogach glacier in 1972. There, melting under the moraine cover of $1-2 \mathrm{~cm}$ of thickness amounted to $95 \%$ of pure ice melting, under $2-3 \mathrm{~cm}-93 \%, 5 \mathrm{~cm}$ $-60 \%, 10 \mathrm{~cm}-54 \%, 15 \mathrm{~cm}-50 \%, 25 \mathrm{~cm}-42 \%, 50 \mathrm{~cm}-15 \%$ (Kuznetsov, 1982).

In spite of a distinct domination of physical ablation over the mechanical one there are regions in the Pamirs where mechanical ablation significantly accelerates the decrease of mass of the glaciers. Ice and snow avalanches, blowing away of snow as well as detaching of the masses of dead ice from the glacier takes place first of all on the slopes of the highest ranges: Peter I, Academy of Sciences, Darvaz, Vanchsky and Zaalaysky (Fig. 4).

\section{MOVEMENT OF GLACIERS}

The velocity of the glaciers' movement changes over time. The main reason of these changes is constituted by the variation of rate of bottom 
sliding, resulting from the changes in water pressure at the glacier's bottom. The best known in the Pamirs with this respect is the Fedchenko glacier. Its average flow velocity amounts to $73 \mathrm{~cm}$ per day $(65-90 \mathrm{~cm}$ per day), see Table 2 (Sokolov, 1982).

The lowest rate of glaciers' flow is observed in the Pamirs in the autumn (September, October). During winter and spring flow velocity increases gradually reaching its maximum in summer (June, July). The summer acceleration is connected with appearance of a greater volumes of water from the melting snow and ice.

Table 2

Flow velocity of Tajikistan glaciers (after Sokolov, 1982)

\begin{tabular}{|l|l|c|c|c|}
\hline \multicolumn{1}{|c|}{ Glacier name } & \multicolumn{1}{|c|}{ Glacier type } & $\begin{array}{c}\text { Surface } \\
\text { in sq.km }\end{array}$ & \multicolumn{2}{c|}{ Flow velocity } \\
\cline { 4 - 5 } & & & cm/day & m/year \\
\hline GGP & kar (Alay) & 0.6 & $1.3-1.5$ & $5.0-5.5$ \\
Skogach & valley & 12.0 & $35-45$ & $130-155$ \\
Geographical Society & valley (dendrite) & 98.0 & $40-60$ & $150-220$ \\
Fedchenko & valley (dendrite) & 651.7 & $65-90$ & $240-330$ \\
\hline
\end{tabular}

Flow velocity of glaciers changes not only in time, but also in space. The greatest values in the transversal cross-section are observed in the middle part at the surface, and then decreases towards the bottom and the sides. Likewise, flow velocity is uneven along the longitudinal cross-section. The distribution of velocity along the axis depends upon the shape of the tongue, slope angle of the rock bed, as well as the ratio of surfaces of the supply area to the spread area. Most often the values at the two extremes are close to zero. The velocity increases from the highest parts of the glacier towards the snow line, reaching its maximum slightly below this line, and then decreases. The longer the glacier the bigger the changes of velocity in the longitudinal profile. Flow velocity in the middle part of the tongue of the Fedchenko Glacier amounts to $90 \mathrm{~cm} /$ day and decreases to $27 \mathrm{~cm} /$ day in the lower part. Flow velocity of Geographical Society glacier below the snow line decreases by $6 \mathrm{~cm} /$ day per one kilometer of length, while the velocity of the Skogach glacier - by $10 \mathrm{~cm} /$ day (Sokolov, 1982).

The velocity of movement per unit of length is not always constant. The increase of velocity in one part of the glacier may be accompanied by the decrease in its other parts. When the increment of mass in the supply area is bigger than its loss in the melting area, the velocity increases and the glacier is lowering its lower limit. Observations of the changes in the glacier stretches were conducted in various areas of the Pamirs in more than 20 stations. These observations indicate that the majority of the Pamirs glaciers remains stationary or transgress (Sokolov, 1982). 
In present times the greatest surface of glaciation in the Pamirs occurs in their western and north-western parts. As can be concluded from the characterization provided here the appearance of glaciers is first of all conditioned by orography, absolute altitudes and climatic features. The Eastern Pamirs, in distinction from the Western part, displays a low degree of contemporary glaciation.

\section{REFERENCES}

Bol'shaya Sovetskaya Entsiklopediya, 1975, (Great Soviet Encyclopedia), Moskva.

Dolgushin L.D., Osipova G.B., 1989, Srednieaziatskii Raion (Middle Asian Region), in: Ledniki. Priroda Mira (Glaciers. Nature of the World). Mys'l, Moskva.

Kuznetsov N.A., 1982, Ablatsiya i lednikovyi stok r'ek [Ablation and the glacial flov of rivers], in: Tajikistan (priroda i prirodnyie r'esursy), Donish, Dushanbe.

Kv a ch e v V.I., 1982, Razmiery ol'edzeniya [Dimensions of glaciation], in: Tajikistan (priroda i prirodnyie r'esursy), Donish, Dushanbe.

S a n nik ov A.G., 1982, Firnovaya liniya (Firn line), in: Tajikistan (priroda i prirodnyie r'esursy). Donish, Dushanbe.

Sok olov L.N., 1982, Dvizheniye l'ednikov (Movement of glaciers), in: Tajikistan (priroda i prirodnyie r'esursy), Donish, Dushanbe. 